\title{
Effects of niflumic acid on $\gamma$-aminobutyric acid-induced currents in isolated dorsal root ganglion neurons of neuropathic pain rats
}

\author{
LI-JIE WANG $^{1 *}$, YANG WANG ${ }^{1-3 *}$, MENG-JIE CHEN $^{1}$, ZHEN-PU TIAN $^{1}$, BI-HAN LU $^{1}$, \\ KE-TAO MAO ${ }^{1,2}$, LIANG ZHANG ${ }^{1,2}$, LEI ZHAO ${ }^{1,2}$, LI-YA SHAN $^{1,2}$, LI LI $^{1,2}$ and JUN-QIANG SI ${ }^{1-4}$ \\ ${ }^{1}$ Department of Physiology; ${ }^{2}$ The Key Laboratory of Xinjiang Endemic and Ethnic Diseases, \\ Shihezi University Medical College, Shihezi, Xinjiang 832002; ${ }^{3}$ Department of Physiology, \\ Wuhan University School of Basic Medical Sciences, Wuhan, Hubei 430071; ${ }^{4}$ Department of Physiology, \\ Huazhong University of Science and Technology, Wuhan, Hubei 430070, P.R. China
}

Received June 26, 2016; Accepted April 10, 2017

DOI: $10.3892 /$ etm.2017.4666

\begin{abstract}
Niflumic acid (NFA) is a type of non-steroidal anti-inflammatory drug. Neuropathic pain is caused by a decrease in presynaptic inhibition mediated by $\gamma$-aminobutyric acid (GABA). In the present study, a whole-cell patch-clamp technique and intracellular recording were used to assess the effect of NFA on GABA-induced inward current in dorsal root ganglion (DRG) neurons of a chronic constriction injury (CCI) model. It was observed that $1-1,000 \mu \mathrm{mol} / 1$ GABA induced a concentration-dependent inward current in DRG neurons. Compared with pseudo-operated rats, the thermal withdrawal latency (TWL) of CCI rats significantly decreased $(\mathrm{P}<0.01)$; however, the TWLs of each NFA group (50 and $300 \mu \mathrm{mol} / \mathrm{l})$ were significantly longer than that of the CCI group $(\mathrm{P}<0.01)$. In the CCI group, the response evoked by GABA $\left(10^{-6}-10^{-3} \mathrm{~mol} / \mathrm{l}\right)$ was reduced in a concentration dependent manner compared with a normal control group $(\mathrm{P}<0.01)$, and the current amplitudes of CCI rats activated by the same concentrations of $\operatorname{GABA}\left(10^{-6}-10^{-3} \mathrm{~mol} / \mathrm{l}\right)$ were significantly decreased compared
\end{abstract}

Correspondence to: Professor $\mathrm{Li} \mathrm{Li}$ or Dr Jun-Qiang $\mathrm{Si}$, Department of Physiology, Shihezi University Medical College, 1 Beier Road, Shihezi, Xinjiang 832002, P.R. China

E-mail: 1ily7588@163.com

E-mail: sijunqiang@shzu.edu.cn

*Contributed equally

Abbreviations: GABA, $\gamma$-aminobutyric acid; $\mathrm{GABA}_{\mathrm{A}} \mathrm{R}$, $\gamma$-aminobutyric acid type A receptor; $\mathrm{CaCC}$, calcium-activated chloride channel; CCI, chronic constriction injury; DRG, dorsal root ganglion; PAD, primary afferent depolarization; NFA, niflumic acid; NSAIDs, non-steroidal anti-inflammatory drugs; NMDA, non-N-Methyl-D-aspartic acid; TWL, thermal withdrawal latency

Key words: niflumic acid, neuropathic pain, dorsal root ganglion, $\gamma$-aminobutyric acid, calcium-activated chloride channel, intracellular recording, whole-cell patch-clamp, immunofluorescence, paw withdrawal latency with the control group $(\mathrm{P}<0.05)$. The inward currents activated by $100 \mu \mathrm{mol} / 1$ GABA were suppressed by treatment with 1,10 and $100 \mu \mathrm{mol} / 1 \mathrm{NFA}(5.32 \pm 3.51,33.8 \pm 5.20$, and $52.2 \pm 6.32 \%$, respectively; $\mathrm{P}<0.05)$. The inverse potentials of GABA-induced currents were $9.87 \pm 1.32$ and $9.64 \pm 1.24 \mathrm{mV}$ with and without NFA, respectively $(\mathrm{P}<0.05)$. Pre-treatment with NFA exerted a strong inhibitory effect on the peak value of GABA-induced current, and the GABA-induced response was inhibited by the same concentrations of NFA $(1,10$ and $100 \mu \mathrm{mol} / \mathrm{l})$ in the control and CCI groups $(\mathrm{P}<0.05)$. The results suggest that NFA reduced the primary afferent depolarization (PAD) associated with neuropathic pain and mediated by the $\mathrm{GABA}_{\mathrm{A}}$ receptor. NFA may regulate neuropathic pain by inhibiting dorsal root reflexes, which are triggered PAD.

\section{Introduction}

Neuropathic pain is defined as pain initiated or caused by a primary lesion or dysfunction in the nervous system, which often presents as spontaneous pain and produces a sense of pain similar to that generated by noxious stimuli, including mechanical and thermal stresses (1). Neuropathic pain seriously impedes patient quality of life. The electrophysiological basis of neuropathic pain is related to an increase in the expression of $\mathrm{Na}^{+}$and voltage-gated $\mathrm{Ca}^{2+}$ channels on the neuronal membrane of injured nerve sites, and the release of an excitatory neurotransmitter, which changes the normal physiological activity of neurons and aggravates neural responses to non-injurious and minor injurious peripheral stimulation $(2,3)$. A large number of neurons spontaneously discharge and release ectopic impulses to the spinal neurons, which increases the sensitivity of spinal neurons and transmission between the synapses and neurotransmitters, thus increasing spinal excitability and causing abnormalities in sensory function (4).

$\gamma$-aminobutyric acid (GABA) in the central nervous system serves an important role in the processing of nociceptive information and the modulation of pain, and is the main inhibitory neurotransmitter (5). It has previously been demonstrated that GABA type A receptors $\left(\mathrm{GABA}_{\mathrm{A}} \mathrm{Rs}\right)$ are involved in the transmission of pain $(5,6)$. $\mathrm{GABA}_{\mathrm{A}} \mathrm{Rs}$ are ligand-gated chloride ion channel receptors $(5,6)$. A previous 
study by our group demonstrated that calcium-activated chloride channels (CaCCs) serve a critical role in the generation of GABA-induced inward currents in the dorsal root ganglions (DRGs) of rats (7). DRGs connect the peripheral and central nervous systems, and GABA and $\mathrm{GABA}_{\mathrm{A}} \mathrm{R}$ are present in the DRG neurons of humans and animals (8). GABA $\mathrm{A}$ receptors in the DRG serve an important role in alleviating the symptoms of neuropathic pain $(9,10)$.

Dorsal root reflexes were first systematically investigated in the 1930s $(11,12)$, and were found to be triggered by primary afferent depolarization (PAD). The stimulation of primary afferent fibers produces PAD, which is blocked by $\mathrm{GABA}_{\mathrm{A}}$ antagonists such as picrotoxin and bicuculline, and also by antagonists of non-N-Methyl-D-aspartic acid (NMDA) glutamate receptors $(13,14)$. The most likely explanation for this is that primary afferent fibers release excitatory amino acids, which then activate non-NMDA glutamate receptors on GABAergic interneurons, causing them to release GABA at axoaxonic or dendroaxonic synapses on primary afferent terminals (13). Possible reasons for an increase in dorsal root reflexes during inflammation include an upregulation of the GABA system in the dorsal horn via the action of signal transduction pathways (14). However, the superimposition of an excitatory mechanism (dorsal root reflexes) onto an inhibitory one (presynaptic inhibition due to PAD) may have negative effects (11). Instead of inhibition, hyperalgesia and allodynia may result from the central effects of dorsal root reflexes, and neurogenic inflammation may result from the peripheral effects (11).

Niflumic acid (NFA) is a type of non-steroidal anti-inflammatory drug (NSAID). NSAIDs are the most widely used pharmacological agents and exhibit a demulcent effect, principally by reducing the synthesis of prostaglandins via inhibition of cyclooxygenase at sites of pain and inflammation (15). NFA, a GABA ${ }_{A} R$ antagonist, is the only chloride ion channel blocker able to protect cells from excitotoxicity (16). It has been suggested that NSAIDs modulate $\mathrm{GABA}_{\mathrm{A}} \mathrm{R}$ function in heterologous expression systems (17). Chronic constriction injury (CCI) models were first used in 1988 and are now widely used in the study of neuropathic pain (18). The surgical techniques used to establish CCI models have many advantages, including a simple surgical procedure and small wound size, and the signs and symptoms of stable spontaneous pain, heat hyperalgesia and mechanical allodynia are similar to those observed clinically (18). In a previous study, the current authors demonstrated that NAF could inhibit GABA-induced current of dorsal root ganglion neurons in both control and CCI, but the mechanism was still unclear (19). The aim of the present study was to investigate the effects of NFA on GABA-induced currents in the dorsal root ganglion neurons of rats with neuropathic pain, and to evaluate the analgesic mechanism of NFA.

\section{Materials and methods}

Materials. A total of 40 healthy male Sprague-Dawley rats aged 8-10 weeks and weighing 250-280 g, were provided by the Experimental Animal Center of Xinjiang Medical University (Urumqi, China). Rats were housed in separate cages in a specific pathogen-free level barrier environment at $24 \pm 3^{\circ} \mathrm{C}$, relative humidity of $40-70 \%$ and a 12 -h light-dark cycle, and were provided with free access to food and water. The study was approved by the ethics committee of The First Affiliated Hospital of Shihezi University Medical College (Shihezi, China).

Establishment of the rat CCI models. A total of 40 rats were randomly divided into three groups: Control group $(n=10)$, sham operation group $(n=10)$ and CCI group $(n=20)$. Rats were anesthetized with an intraperitoneal injection of $10 \%$ (w/v) sodium chloral hydrate $[350 \mathrm{mg} / \mathrm{kg}$ body weight, Sangon Biotech (Shanghai) Co., Ltd., Shanghai, China], and the left sciatic nerve trunk was exposed under sterile conditions. The skin was longitudinally cut and muscle was dissociated by blunt dissection to fully expose the sciatic nerve, proximal to the sciatic trifurcation. Approximately $5 \mathrm{~mm}$ of nerve was freed, and 4 tight ligatures of chrome catgut were placed around the sciatic nerve with $\sim 1 \mathrm{~mm}$ spacing. The tightness of ligatures was such that the blood supply to the epineurium was not affected. Rats in thee pseudo-operated groups underwent the same procedure but were not ligated. Rats were fed normally to recover post-surgery. To assess whether the model had been successfully established, paw withdrawal latency was assessed, as described previously (20), and in the model group values from the $\mathrm{CCI}$ ipsilateral side were significantly declined by $\geq 30 \%$ ( $\mathrm{P}<0.05)$, which indicated modeling success. A total of 10 rats were randomly selected from each group.

Hot plate testing. To determine whether the CCI model had been successfully established, paw withdrawal latency was assessed (20). A Plantar Test (Hargreaves Apparatus; cat. no. 37370) was purchased from Ugo Basile S.R.L (Monvalle, Italy). The Plantar Test was used in accordance with the manufacturer's protocol. Thermal hyperalgesia was measured using an infrared intensity of 50, and expressed as paw withdrawal latency of the left hind paw. The mean of three measurements at 4-min intervals was regarded as the paw withdrawal latency. In order to prevent tissue damage, the maximum latency was defined as $30 \mathrm{sec}$, following which rats were removed from the plantar testing apparatus. Plantar testing was performed at the following time points: Pre-surgery and on days 1, 3, 5, 7, 10 and 14 post-surgery. Following plantar testing at each time point, rats were prepared for experimentation.

Electrophysiological recordings of dorsal root ganglion neurons. Rats were anesthetized with an intraperitoneal injection of $10 \%$ (w/v) sodium chloral hydrate $(350 \mathrm{mg} / \mathrm{kg}$ body weight) and decapitated, and the cervical, thoracic and lumbar spine was immediately harvested. The spine was split longitudinally and placed in an extracellular fluid substitute, the composition of which was as follows: $150 \mathrm{mmol} / \mathrm{l} \mathrm{NaCl}$, $5 \mathrm{mmol} / 1 \mathrm{KCl}, 2.5 \mathrm{mmol} / \mathrm{l} \mathrm{CaCl}{ }_{2}, 1 \mathrm{mmol} / 1 \mathrm{MgCl}_{2}, 10 \mathrm{mmol} / \mathrm{l}$ HEPES (H3375; Sigma-Aldrich; Merck KGaA, Darmstadt Germany), 10 mmol/l D-glucose [A600219-0001; Sangon Biotech (Shanghai) Co., Ltd.], and $\mathrm{NaOH}$ to give a pH of 7.3-7.4 (osmotic pressure $=330 \mathrm{mOsm}$ ). Ganglia and the associated nerve roots were individually removed under a stereomicroscope. The trimmed DRG was cut into pieces using eye scissors and transferred to an eppendorf (EP) tube that contained $0.25 \mathrm{mg} / \mathrm{ml}$ trypsinase (T1426; Sigma-Aldrich; Merck KGaA) 
and $0.5 \mathrm{mg} / \mathrm{ml}$ collagenase (C0130; Sigma-Aldrich; Merck $\mathrm{KGaA})$. The EP tube was incubated at $37^{\circ} \mathrm{C}$ for $12 \mathrm{~min}$, then mixed with $0.1 \mathrm{mg} / \mathrm{ml}$ trypsin inhibitor (T6522; Sigma-Aldrich; Merck KGaA) to cease digestion and centrifuged at $300 \mathrm{x}$ g for $6 \mathrm{~min}$. The supernatant was discarded and 2-3 ml extracellular fluid substitute was added for patch-clamp experiments and left to stand for at least $30 \mathrm{~min}$ at room temperature to allow cells to adhere. Whole-cell patch clamp recordings were performed at room temperature using a whole-cell patch clamp amplifier. Briefly, currents were recorded from single dorsal root ganglion neurons in vitro using an Axon $700 \mathrm{~B}$ amplifier (Molecular Devices, LLC, Sunnyvale, CA, USA) and the pCLAMP 10.2 hardware and software (Molecular Devices, LLC). Microelectrodes ( $\sim \mu$ m diameter) were pulled using a P-97 puller (Sutter Instrument Co., Novato, CA, USA), and the impedance of each glass microelectrode was 3-5 M $\Omega$. Microelectrodes were filled with internal solution containing $140 \mathrm{mmol} / 1 \mathrm{KCl}, 1 \mathrm{mmol} / 1 \mathrm{CaCl}_{2}, 2 \mathrm{mmol} / 1 \mathrm{MgCl}_{2}, 10 \mathrm{mmol} / \mathrm{l}$ HEPES and $11 \mathrm{mmol} / \mathrm{l} \mathrm{EGTA}$, and $\mathrm{KOH}(1 \mathrm{~mol} / \mathrm{l})$ to raise the $\mathrm{pH}$ to 7.3-7.4. Separated single cells that had adhered well and exhibited round or oval morphology, a clear shape and contour, membrane integrity, a uniform cytoplasm and a diameter of 15-45 $\mu \mathrm{m}$ were selected under an inverted microscope. The glass microelectrode was moved onto the cell surface using a micromanipulator (CV-7B; Molecular Devices, LLC, Sunnyvale, CA, USA). Vacuum suction was applied to form a high-resistance seal between the electrode and cell membrane, and the capacitance and series resistance were adjusted to maintain a voltage of $-60 \mathrm{mV}$, as described previously $(21,22)$.

Pharmacological agents were prepared with sugar-free extracellular fluid (as described above but without D-glucose). The drug delivery system comprised a micromanipulator which allowed rapid changing of drug delivery tubes. The diameter of every drug delivery tube was $0.5 \mathrm{~mm}$ and the distance between nozzle and cell was $100 \mu \mathrm{m}$. GABA (A5835; Sigma-Aldrich; Merck KGaA) (1-1,000 $\mu \mathrm{mol} / \mathrm{l})$ was administered from low to high concentration for 5-6 sec to establish a 'front control', with an intermission of 4 min during which cells were bathed in extracellular fluid. Bicuculline (285269; Sigma-Aldrich; Merck KGaA) was administered at $100 \mu \mathrm{mol} / 1$. The same concentration of GABA was perfused as the front control. Prior to administering the mixture of NFA (1, 10 and 100 mmol/l; N0630-25 G; Sigma-Aldrich; Merck $\mathrm{KGaA})$ and GABA $(100 \mu \mathrm{mol} / \mathrm{l})$, NFA $(1,10,100 \mu \mathrm{mol} / \mathrm{l})$ was pre-perfused for $20 \mathrm{sec}$. After the GABA-activated current $\left(\mathrm{I}_{\mathrm{GABA}}\right)$ was steady and the cells had been bathed for $4 \mathrm{~min}$, the mixture of GABA and NFA was perfused for $5 \mathrm{sec}$, when the $\mathrm{I}_{\mathrm{GABA}}$ recovered to the level of the front control, the other concentrations of NFA were perfused. The inhibitory effects of different concentrations of NFA on $\mathrm{I}_{\mathrm{GABA}}$ were recorded and the inhibitory rate of NFA on $\mathrm{I}_{\mathrm{GABA}}$ was calculated using the following formula: $\left(\mathrm{I}_{\mathrm{GABA}}-\mathrm{I}_{\text {mixture }}\right) / \mathrm{I}_{\mathrm{GABA}} \mathrm{x} 100(22,23)$.

$D R G$ preparation and intracellular recording. A total of 20 male Wistar rats (age 2-3 weeks; weight, 200-250 g) were purchased from Xinjiang Medical University. Rats were housed in cages in a specific pathogen-free level barrier environment at $24 \pm 3^{\circ} \mathrm{C}$, relative humidity of $40-70 \%$ and a 12-h light/dark cycle, with free access to food and water. Rats were anesthetized with an intraperitoneal injection of $10 \%$ (w/v) sodium chloral hydrate $(350 \mathrm{mg} / \mathrm{kg}$ body weight) and decapitated, and the cervical, thoracic and lumbar spine was immediately harvested. The rats subsequently underwent a laminectomy at $\mathrm{L}_{4}$ or $\mathrm{L}_{5}$. DRGs with attached dorsal roots and spinal nerves were harvested and the fibrous sheath surrounding the DRG was removed under the stereoscope. The isolated preparation was transferred into a recording chamber $(0.25 \mathrm{ml}$ volume $)$, and perfused with oxygenated balanced salt solution (BSS) at room temperature. The BSS contained $140 \mathrm{mmol} / 1 \mathrm{NaCl}, 5 \mathrm{mmol} / \mathrm{l} \mathrm{KCl}, 1 \mathrm{mmol} / 1 \mathrm{MgCl}_{2}$, $5 \mathrm{mmol} / 1$ glucose and $5 \mathrm{mmol} / \mathrm{l}$ Tris-HCl (RES3098T-B701X; Sigma-Aldrich; Merck KGaA) (pH 7.4). The flow rate was $3-5 \mathrm{ml} / \mathrm{min}$. The preparation was pinned with small steel pins $(0.5 \mathrm{~mm})$ onto a silicone gum block, which was placed in the chamber. The sciatic nerve was placed on a pair of platinum stimulating electrodes in the neighboring compartment, as described previously (9).

Intracellular recordings were obtained using a glass microelectrode (1 $\mathrm{mm}$ diameter) filled with $2 \mathrm{~mol} / 1 \mathrm{KCl}$ and $1 \mathrm{~mol} / \mathrm{l}$ potassium acetate, the impedance of each glass microelectrode was in the range of 25-60 M . Membrane potentials were amplified with a microelectrode amplifier (MEZ-8301; Nihon Kohden, Tokyo, Japan) and membrane depolarization was filtered at $20 \mathrm{~Hz}$ (as previously described) (9). Data were recorded with a pen recorder (cat. no. XWTD-264; Shanghai Instrument Group Co., Ltd., Shanghai, China). The values acquired for resting membrane potentials used in the preparations were stable for $10-20 \mathrm{~min}$.

Statistical analysis. Data were analyzed with SPSS 17.0 software (SPSS, Inc., Chicago, IL, USA) and presented as the mean \pm standard error of the mean. A homogeneity test for variance was performed followed by one-way analysis of variance, and two-group comparisons were conducted using the least significant difference t-test. $\mathrm{P}<0.05$ was considered to indicate a statistically significant difference for all experiments.

\section{Results}

Characteristics of GABA-induced currents in dorsal root ganglion neurons. GABA (1-1,000 $\mu \mathrm{mol} / \mathrm{l})$ administration induced a concentration-dependent inward current in DRG neurons (Fig. 1A). This reaction was significantly blocked by the $\mathrm{GABA}_{\mathrm{A}} \mathrm{R}$ selective antagonist, bicuculline $(100 \mu \mathrm{mol} / \mathrm{l}$; $\mathrm{P}<0.01$; Fig. 1B and $\mathrm{C}$ ), illustrating the GABA-induced inward current induced by the $\mathrm{GABA}_{\mathrm{A}} \mathrm{R}$.

Effects of NFA on thermal hyperalgesia in CCI rats. The effects of CCI on behavioral displays of hyperalgesia were investigated using plantar testing. The thermal withdrawal latency (TWL) of CCI rats significantly decreased from days 1 to 14 post-surgery compared with the control $(\mathrm{P}<0.01)$, and peaked on days 3-7 (Fig. 2). This is in accordance with a previous study performed by our group (20). The TWLs of each of the NFA groups were significantly longer than in the CCI group $(\mathrm{P}<0.05$; Fig. 2). Furthermore, TWL in the $50 \mu \mathrm{mol} / 1 \mathrm{NFA}$ group was significantly longer than in the $10 \mu \mathrm{M}$ NFA group ( $\mathrm{P}<0.05$; Fig. 2); however, no significant differences were observed between the 300 and $50 \mu \mathrm{mol} / 1$ NFA groups. 
A
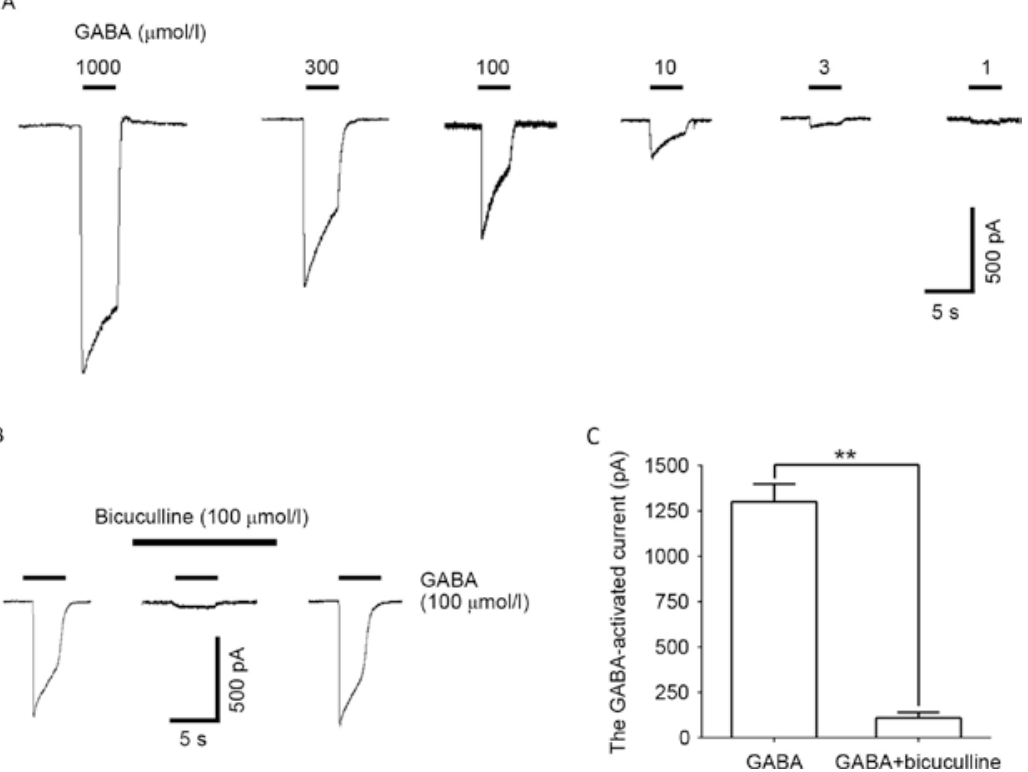

Figure 1. Concentration dependence of GABA-induced inward currents. (A) Sequential current-traces illustrating the concentration-dependent GABA-induced current amplitude. (B) Blockade of GABA-induced inward current by bicuculline. (C) Statistical results of bicuculline blockade of GABA-induced currents Data are expressed as the mean \pm standard error of the mean $(n=8) .{ }^{* *} \mathrm{P}<0.01$ vs. GABA group. GABA, $\gamma$-aminobutyric acid.

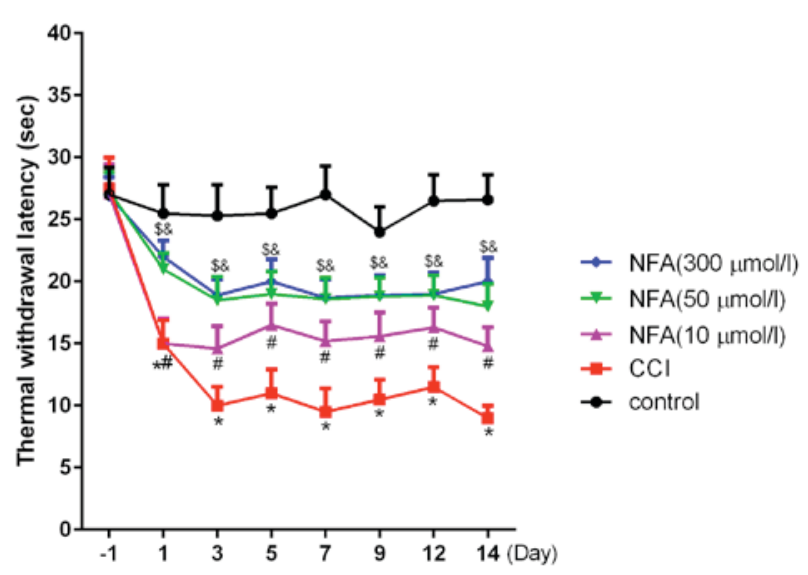

Figure 2. Paw withdrawal latency of rats following CCI in the sciatic nerve and the effect of NFA. Withdrawal thresholds to thermal stimulation were measured using a Plantar Test. Tests were performed on day 1 prior to surgery and on days $1,3,5,7,9,12$ and 14 post-surgery. Thermal hyperalgesia of the CCI group was indicated by a significant reduction in paw withdrawal latency. Latency was prolonged by NFA in a dose-dependent manner. Withdrawal latency did not differ significantly between the 50 and $300 \mu \mathrm{mol} / 1 \mathrm{NFA}$ intervention groups. Data are expressed as the mean \pm standard error of the mean. $\mathrm{n}=10 .{ }^{*} \mathrm{P}<0.01 \mathrm{CCI}$ group vs. control group; ${ }^{\#} \mathrm{P}<0.0510 \mu \mathrm{mol} / 1 \mathrm{vs}$. CCI group; ${ }^{\&} \mathrm{P}<0.05,50 \mu \mathrm{mol} / 1 \mathrm{NFA}$ vs. CCI group ${ }^{\$} \mathrm{P}<0.05,300 \mu \mathrm{mol} / 1 \mathrm{NFA}$ vs. CCI group. CCI, chronic constriction injury; NFA, niflumic acid.

GABA-induced depolarization in the dorsal root ganglion neurons of different groups. In DRG neurons of the normal group, the majority of cells $(90.6 \%)$ were sensitive to the application of GABA $\left(10^{-6}-10^{-3} \mathrm{~mol} / \mathrm{l}\right)$ and exhibited a concentration-dependent depolarizing response. The threshold was $\sim 10^{-6} \mathrm{~mol} / \mathrm{l} \mathrm{GABA}$, and the maximal response was elicited by $1 \times 10^{-3} \mathrm{~mol} / 1$ GABA (Fig. 3A). DRG neurons of the CCI group also exhibited a concentration-dependent depolarizing response; however the GABA-evoked response was reduced at each concentration of GABA when compared with control DRG neurons (Fig. 3A and $\mathrm{B} ; \mathrm{P}<0.01$ ). The half maximal effective concentration $\left(\mathrm{EC}_{50}\right)$ values did not differ significantly between the normal and CCI groups. $\mathrm{EC}_{50}$ values for the normal and CCI groups were $27.43 \pm 3.22$ and $28.16 \pm 2.56 \mu \mathrm{mol} / 1$, respectively.

GABA-induced currents in the dorsal root ganglion neurons of different groups. GABA induced a concentration-dependent inward current in the $\mathrm{L}_{4-6}$ dorsal root ganglion neurons of the control, sham operation and CCI groups (Fig. 4). The amplitudes of GABA-induced currents in CCI rats were significantly depressed compared with the control and pseudo-operated groups $(\mathrm{P}<0.05$; Fig. 4); however, current amplitudes did not differ significantly between the control and pseudo-operated groups. GABA-induced $(100 \mu \mathrm{mol} / \mathrm{l})$ currents in the dorsal root ganglion neurons of the control, pseudo-operated and CCI groups were $1222.3 \pm 71.5,1244.6 \pm 83.2$ and $428.8 \pm 34.4 \mathrm{pA}$, respectively.

Effects of NFA on the inverse potential of GABA-induced currents. Cells were pre-incubated with NFA for $20 \mathrm{sec}$ prior to the application of GABA, resulting in a marked attenuation of the GABA-induced inward current in the majority of the neurons examined (96.3\%). The inhibitory effect of NFA on GABA-induced responses was concentration-dependent. The $100 \mu \mathrm{mol} / \mathrm{l}$ GABA-induced inward currents were suppressed by $5.32 \pm 3.51,33.8 \pm 5.20$ and $52.2 \pm 6.32 \%$ by 1,10 , and $100 \mu \mathrm{mol} / 1 \mathrm{NFA}$, respectively (Fig. 5A). Based on a concentration inhibition curve determined in previous research, the inhibition threshold was $\sim 0.1 \mu \mathrm{mol} / 1 \mathrm{NFA}$, maximal inhibition was achieved at $300 \mu \mathrm{mol} / 1 \mathrm{NFA}$ and the half maximal inhibitory concentration of NFA was $\sim 6.7 \mu \mathrm{mol} / 1$ (24). NFA did not alter the $\mathrm{EC}_{50}$ value of GABA $(\sim 30 \mu \mathrm{mol} / \mathrm{l})(25)$; however, NFA reduced the maximal GABA current by $\sim 60 \%(\mathrm{P}<0.05$, data not shown). In addition, GABA-induced $(100 \mu \mathrm{mol} / \mathrm{l})$ currents were altered at different holding potentials $(-80-40 \mathrm{mV})$ in the 
A

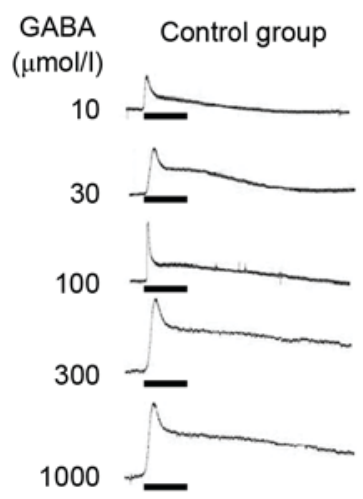

B

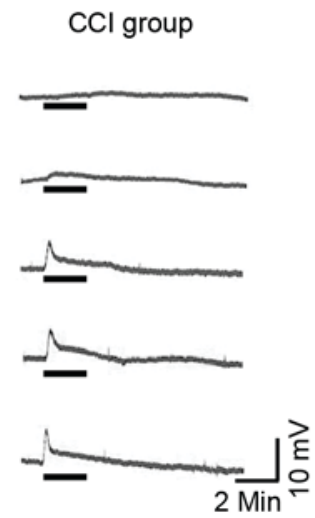

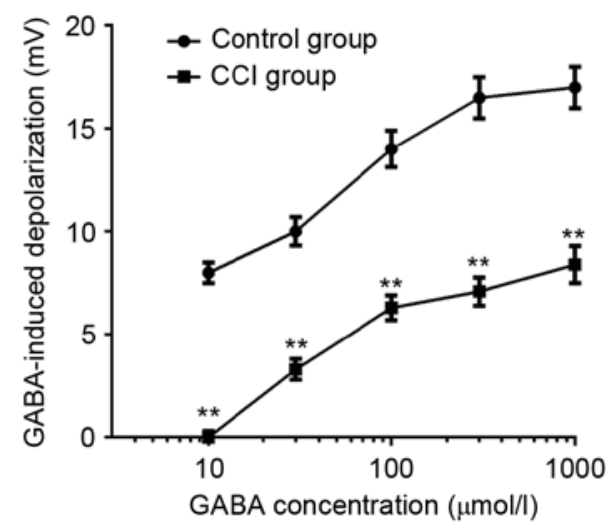

Figure 3. GABA-induced depolarization of DRG neurons of normal and CCI rats. (A) Different concentrations of GABA induced depolarization of DRG neurons in normal and CCI rats. (B) Concentration-response curves of GABA-induced depolarization. Data are expressed as the mean \pm standard error of the mean. $n \geq 6$. ${ }^{* *} \mathrm{P}<0.01$ vs. control. GABA, $\gamma$-aminobutyric acid; DRG, dorsal root ganglion; CCI, chronic constriction injury.

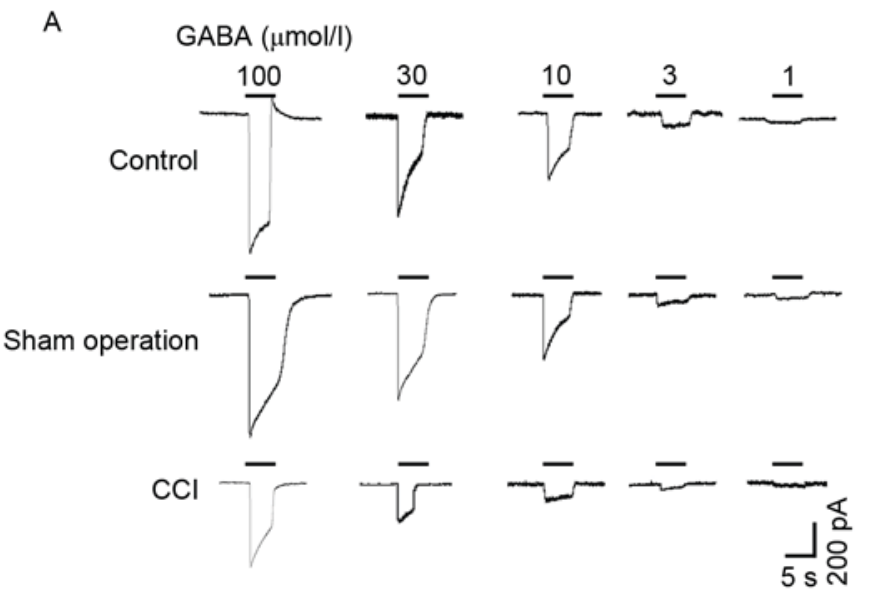

B

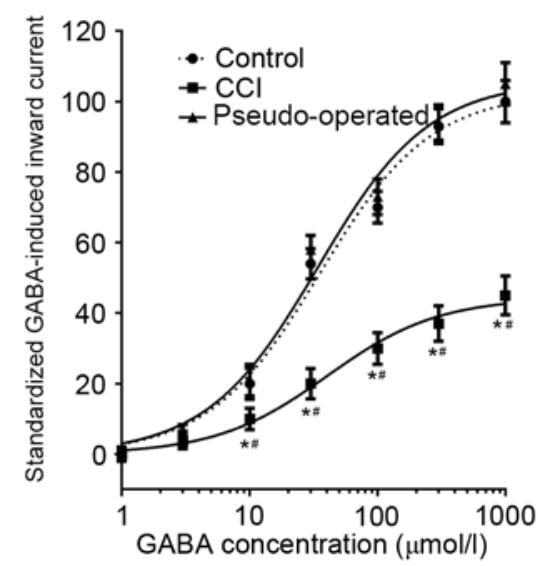

Figure 4. GABA-induced inward currents in DRG neurons. (A) Different concentrations of GABA induced inward currents in the control, sham operation and CCI groups. (B) Concentration-response curves of GABA-induced inward currents. Data are expressed as the mean \pm standard error of the mean. $n=6$. ${ }^{*} \mathrm{P}<0.05$ vs. sham operation group; ${ }^{\prime} \mathrm{P}<0.05$ vs. control group. GABA, $\gamma$-aminobutyric acid; DRG, dorsal root ganglion; $\mathrm{CCI}$, chronic constriction injury.

presence and absence of $100 \mu \mathrm{mol} / 1 \mathrm{NFA}$ (Fig. 5B). The inverse potentials of GABA-induced currents were $-9.87 \pm 1.32$ and $-9.64 \pm 1.24 \mathrm{mV}$ with and without NFA treatment, respectively (Fig. 5C).

Effects of NFA on the desensitization of GABA-induced currents. The inhibitory effect of NFA was found to be concentration-dependent. In previous research, the desensitization of GABA-induced current was notable, as the amplitude of the current decayed exponentially from a peak value and was then maintained at a steady level, despite the constant presence and concentration of GABA. The GABA-induced current included three distinct phases; a peak, a desensitization phase and a steady state. A minority of GABA-induced currents $(<10 \%)$ exhibited only the peak and desensitization phases. The desensitization of GABA-induced currents exhibited double exponential characteristics, and the desensitization current was a bi-exponential function curve, and thus it was a biphasic process, including fast and slow desensitization $(25,26)$. As depicted in Fig. 6, the desensitization curve was a good fit and followed the 2 term exponential equation, $f(t)=\sum A_{i} e^{-t / \tau i}+C$ (blue lines). In this equation, $\mathrm{A}_{\mathrm{i}}$ was GABA-induced currents, $\tau$ was the time constant of GABA-induced currents and $\mathrm{C}$ was a random constant. The $\tau$ value of the desensitization of GABA-induced currents was $14.68 \pm 5.11 \mathrm{sec}$ for fast desensitization and $175.8 \pm 42.67 \mathrm{sec}$ for slow desensitization (Fig. 6). The suppression rate of $100 \mu \mathrm{mol} / 1 \mathrm{NFA}$ on GABA-induced current was $52.2 \pm 6.32 \%$. Pre-application of $100 \mu \mathrm{mol} / 1 \mathrm{NFA}$ altered the $\tau$ value of the desensitization of GABA-induced currents; the $\tau$ value decreased to $4.64 \pm 2.21$ and $43.70 \pm 14.34 \mathrm{sec}$ for fast and slow desensitization, respectively (Fig. 6). Pre-application of NFA exerted a stronger inhibitory effect on the peak value of GABA-induced current, which may accelerate the desensitization of GABA-induced currents.

Inhibition of GABA-induced inward currents by NFA in different groups. When cells were pre-incubated with NFA for $20 \mathrm{sec}$ prior to the application of GABA, NFA induced a concentration-dependent inhibition of the GABA-induced response (Fig. 7). In the control group, the inward currents induced by $100 \mu \mathrm{mol} / 1$ GABA were suppressed by $7.47 \pm 2.75$, $16.85 \pm 0.46,36.65 \pm 1.13,44.66 \pm 5.14$ and $56.81 \pm 7.92 \%$ by 1,3 , 


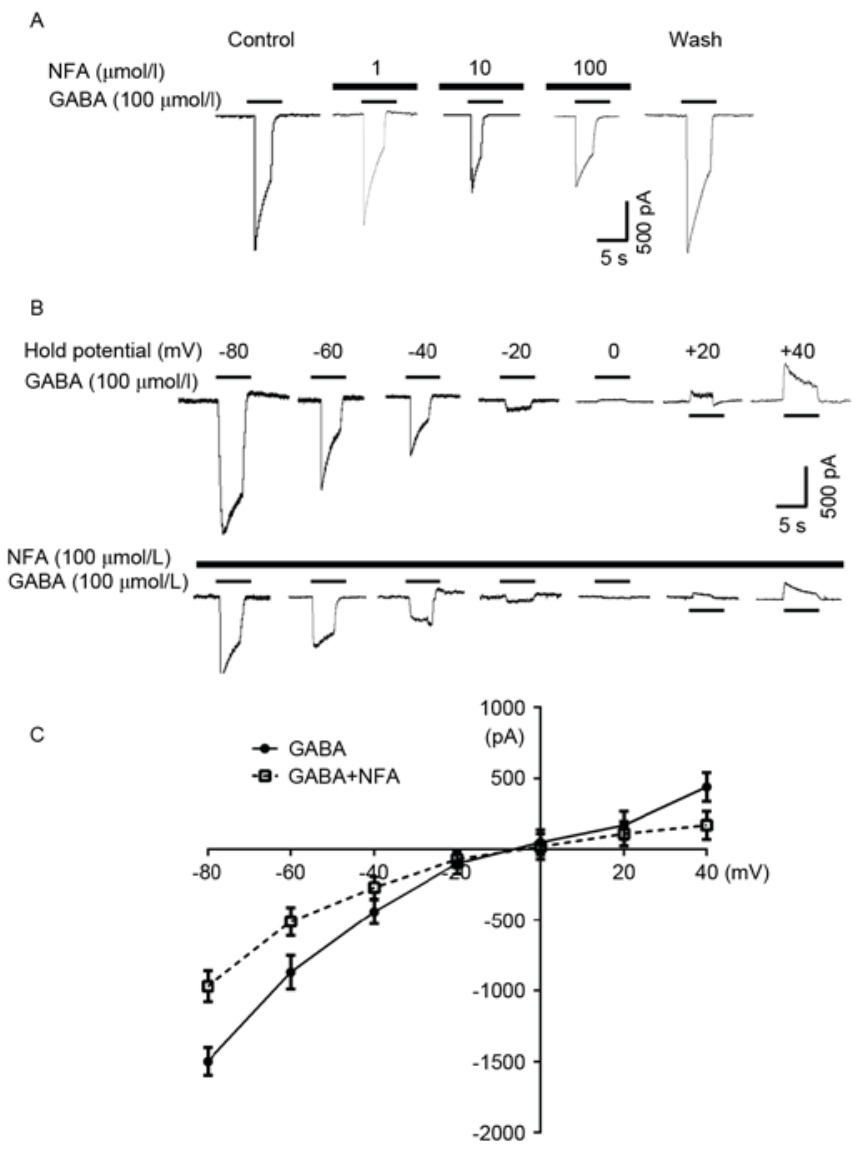

Figure 5. Inhibitory effects of NFA on the inverse potential of GABA-induced inward currents. (A) NFA inhibited GABA-induced responses in a concentration-dependent manner. (B) Tracings of the inverse potential of GABA-induced currents at different holding potentials with and without NFA. (C) Inverse potential of GABA-induced currents at different holding potentials with and without NFA. NFA, niflumic acid; GABA, $\gamma$-aminobutyric acid.

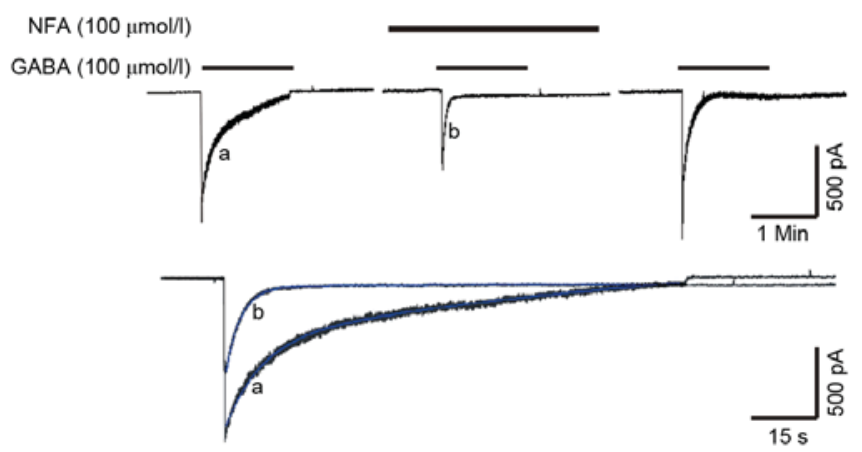

Figure 6. Desensitization of GABA-induced currents with and without NFA. The desensitization curve was a good fit and followed the 2 term exponential equation $\mathrm{f}(\mathrm{t})=\sum \mathrm{A}_{\mathrm{i}} \mathrm{e}^{-\mathrm{t} / \mathrm{i}}+\mathrm{C}$ (blue lines). In this equation, $\mathrm{A}_{\mathrm{i}}$ was $\mathrm{GABA}$-induced currents, $\tau$ was time constant of GABA-induced currents, $C$ was random constant. GABA, $\gamma$-aminobutyric acid; NFA, niflumic acid.

10,30 and $100 \mu \mathrm{mol} / 1 \mathrm{NFA}$, respectively $(\mathrm{P}<0.05)$. In the CCI group the inward currents induced by $100 \mu \mathrm{mol} / \mathrm{l} \mathrm{GABA}$ were suppressed $3.05 \pm 1.92,21.21 \pm 4.02,19.35 \pm 5.66,31.27 \pm 1.75$ and $45.28 \pm 0.86 \%$ by $1,3,10,30$ and $100 \mu \mathrm{mol} / 1 \mathrm{NFA}$, respectively (Fig. 7B). Maximal inhibition was achieved by $100 \mu \mathrm{mol} / 1$ NFA (Fig. 7A and B). The GABA-induced response was

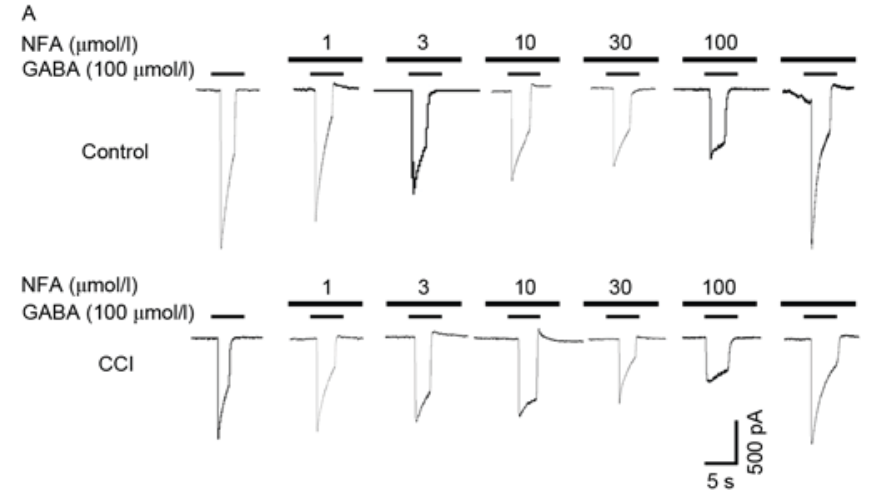

B

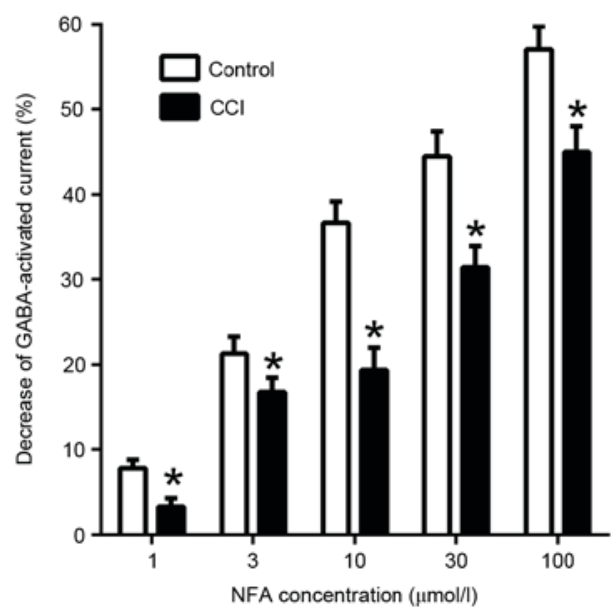

Figure 7. Effects of NFA on GABA-induced inward current. (A) GABA-induced inward currents in the control and CCI groups treated with different concentrations of NFA. (B) The inhibitory effect of NFA on GABA-induced inward currents in the control and CCI groups. Data are expressed as the mean \pm standard error of the mean. $n=5$. ${ }^{*} \mathrm{P}<0.05$ vs. control group. NFA, niflumic acid; GABA, $\gamma$-aminobutyric acid; CCI, chronic constriction injury.

inhibited by NFA in both the control and CCI groups, however inhibition in the CCI group was significantly greater compared with the control group at all concentrations of NFA $(\mathrm{P}<0.05$; Fig. 7B).

\section{Discussion}

In the present study, rats in the CCI group exhibited a reduced TWL, and thus were more sensitive to heat pain, indicating that the CCI model had been successfully established. In a previous study, an antibody against interleukin- 8 was able to significantly increase the TWL of CCI model rats (27), suggesting that the inflammatory reaction serves an important role in CCI models. Patients with inflammatory pain typically exhibit a high sensitivity to heat and may experience unbearable heat pain in the injured area (27). In the establishment of CCI models, ligatures of chrome catgut are placed around the sciatic nerve and sterile inflammation is induced, which damages nerve fibers and causes neuropathic pain. As such, the CCI model includes two types of pain; inflammatory and neuropathic (27).

The present study used a whole-cell recording technique to measure GABA-induced inward currents induced by 
$\mathrm{GABA}_{\mathrm{A}} \mathrm{Rs}$ on the $\mathrm{L}_{4-6}$ dorsal root ganglion neurons of control, pseudo-operated and CCI rats. The amplitudes of currents in CCI rats were significantly depressed compared with control and pseudo-operated rats. As the effects of presynaptic GABA inhibition are primarily implemented by $\mathrm{GABA}_{\mathrm{A}} \mathrm{Rs}$ (28), these results suggest that there is a functional change of $\mathrm{GABA}_{\mathrm{A}} \mathrm{Rs}$ on the CCI ipsilateral side. High levels of spontaneous discharge occur in dorsal root ganglion neurons and nerve fibers following nerve damage, due to weakening of $\mathrm{GABA}_{\mathrm{A}} \mathrm{R}$-induced presynaptic inhibition. This results in the transfer of large amounts of nociceptive information to the spinal cord and above, leading to ultra-sensitized neurons and neuropathic pain (8). Naik et al (8) assessed the symptoms of neuropathic pain in rats with $\mathrm{L}_{5}$ nerve injury, and observed that neuropathic pain was alleviated by the $\mathrm{GABA}_{\mathrm{A}} \mathrm{R}$ agonists, muscinol and gaboxadol, in a dose-dependent manner. In turn, neuropathic pain was aggravated by the $\mathrm{GABA}_{\mathrm{A}}$ receptor antagonists, bicuculline and picrotoxin (8). A previous study by our group demonstrated that chronic crush injury in DRG neurons may alter $\mathrm{GABA}_{\mathrm{A}} \mathrm{Rs}$ and initiate changes in the cytoplasmic cAMP and cGMP signal transduction pathways, thus reducing $\mathrm{GABA}_{\mathrm{A}} \mathrm{R}$ functionality and presynaptic inhibition (29).

The $\mathrm{GABA}_{\mathrm{A}} \mathrm{R}$ is a ligand-gated chloride ion channel receptor. Using the outside-out patch-clamp mode, it has been observed that changes in the concentrations of $\mathrm{Cl}^{-}$on both sides of the cell membrane may alter the reversal potential of GABA single channel currents, indicating that $\mathrm{GABA}_{\mathrm{A}}$ channels may be selective for $\mathrm{Cl}^{-}(11,30)$. Activation of the $\mathrm{GABA}_{\mathrm{A}} \mathrm{R}$ by GABA leading to opening of $\mathrm{Cl}^{-}$channels, and the direction of $\mathrm{Cl}^{-}$flow (influx or efflux) depends on the relative potential of $\mathrm{Cl}^{-}$and the membrane resting potential $(11,31)$. In the peripheral nervous system, including sympathetic ganglion cells, the intracellular concentration of $\mathrm{Cl}^{-}$is greater than the extracellular concentration, and thus the equilibrium potential of $\mathrm{Cl}^{-}$is smaller than the resting potential. As such, when $\mathrm{Cl}^{-}$channels are activated by GABA, the $\mathrm{Cl}^{-}$efflux induces membrane depolarization $(11,12)$.

Aside from being an NSAID, NFA is recognized as a strong CaCC blocker (32). The present results demonstrated that NFA significantly inhibited GABA-induced inward current in the control group. These results suggest that $\mathrm{CaCC}$ s serve a critical role in the generation of GABA-induced inward current in rat DRGs, which is in accordance with previous experimental results (7). The present study also demonstrated that NFA inhibits the GABA-induced response in $\mathrm{L}_{4-6}$ DRG neurons in CCI rats, suggesting that NFA treatment may ameliorate neuropathic pain. A previous study by our group demonstrated that NFA exerted an analgesic effect on persistent pain in rats in a formalin test (20). The inhibitory effects of NFA on the GABA-induced response in CCI rats may have been due to an increase in the number of $\mathrm{CaCCs}$ on the DRG neurons. However, the inhibitory effects of NFA on the GABA-induced response did not differ significantly between the CCI and controls groups. In 2008, three laboratory groups cloned genes that encoded classical CaCCs (33-35), and two of the genes were demonstrated to encode transmembrane member (TMEM) 16A and TMEM 16B, as two CaCC subunits. Immunofluorescence staining was used to assess TMEM 16A expression, and the results demonstrated that TMEM 16A was upregulated in a CCI group 14 days after surgery (unpublished data). This may be responsible for the reduced inhibitory effect of NFA on CCI neurons in the present study, suggesting that NFA may alleviate neuropathic pain.

Cervero and Laird (36) proposed that, during inflammation, dorsal root reflexes in $A_{\beta}$ fibers activate GABAergic inhibitory interneurons, which in turn trigger dorsal root reflexes in $\mathrm{C}$ fibers. This may lead to $\mathrm{C}$ fibers causing pain in response to input from $\mathrm{A}_{\beta}$ fibers, as a mechanism for allodynia (36). As an additional outcome of increased dorsal root reflexes during inflammation, Willis (11) suggested that dorsal root reflexes may propagate peripherally and release neurotransmitter substances, including neurotransmitter peptides, into the joints, skin and other peripheral tissues, which may induce the initial stages of neurogenic inflammation.

Dorsal root reflexes are conducted centrifugally to peripheral sensory endings, where they release neurotransmitters and/or alter the excitability of sensory terminals (11). They also propagate centripetally and release neurotransmitters that affect the excitability of interneurons and motoneurons (11). PAD, which is normally an inhibitory event, may be converted into an excitatory event when dorsal root reflexes are triggered. Thus, PAD may be a double-edged sword; generally inhibitory, but excitatory when dorsal root reflexes are triggered (11). NFA may mediate neuropathic pain by inhibiting dorsal root reflexes, which are triggered by GABA-induced inward currents in the primary afferent nerve endings leading to PAD. Thus, NSAIDs may have potential benefits in the treatment of neuropathic pain.

\section{Acknowledgements}

The present study was supported by the National Natural Science Foundation of China (grant no. 30160026) and the Youth Science and Technology Innovation Special Foundation of Xinjiang Production and Construction Corps (grant no. 2010JC33).

\section{References}

1. Heydari M, Shams M, Hashempur MH, Zargaran A, Dalfardi B and Borhani-Haghighi A: The origin of the concept of neuropathic pain in Early Medieval Persia (9th-12th century CE). Acta Med Hist Adriat 13 (Suppl): S9-S22, 2015.

2. Markman JD and Dworkin RH: Ion channel targets and treatment efficacy in neuropathic pain. J Pain 7 (1 Suppl 1): S38-S47, 2006.

3. Bourinet E, Francois A and Laffray S: T-type calcium channels in neuropathic pain. Pain 157 (Suppl 1): S15-S22, 2016.

4. Tsuda M: Microglia in the spinal cord and neuropathic pain. J Diabetes Investig 7: 17-26, 2016.

5. Bravo-Hernández M, Corleto JA, Barragán-Iglesias $\mathrm{P}$, González-Ramírez R, Pineda-Farias JB, Felix R, Calcutt NA, Delgado-Lezama R, Marsala M and Granados-Soto V: The $\alpha 5$ subunit containing GABAA receptors contribute to chronic pain. Pain 157: 613-626, 2016

6. Maddox FN, Valeyev AY, Poth K, Holohean AM, Wood PM, Davidoff RA, Hackman JC and Luetje CW: GABAA receptor subunit mRNA expression in cultured embryonic and adult human dorsal root ganglion neurons. Brain Res Dev Brain Res 149: 143-151, 2004.

7. Zhao L, Li LI, Ma KT, Wang Y, Li J, Shi WY, Zhu HE, Zhang ZS and Si JQ: NSAIDs modulate GABA-activated currents via $\mathrm{Ca} 2+$-activated $\mathrm{Cl}$ channels in rat dorsal root ganglion neurons. Exp Ther Med 11: 1755-1761, 2016. 
8. Naik AK, Pathirathna S and Jevtovic-Todorovic V: GABAA receptor modulation in dorsal root ganglia in vivo affects chronic pain after nerve injury. Neuroscience 154: 1539-1553, 2008.

9. Ma KT, Si JQ, Zhang ZQ, Zhao L, Fan P, Jin JL, Li XZ and Zhu L: Modulatory effect of CCK-8S on GABA-induced depolarization from rat dorsal root ganglion. Brain Res 1121: 66-75, 2006.

10. Zhao X, Li XL, Liu X, Wang C, Zhou DS, Ma Q, Zhou WH and Hu ZY: Antinociceptive effects of fisetin against diabetic neuropathic pain in mice: Engagement of antioxidant mechanisms and spinal GABAA receptors. Pharmacol Res 102: 286-297, 2015.

11. Willis WD Jr: Dorsal root potentials and dorsal root reflexes: A double-edged sword. Exp Brain Res 124: 395-421, 1999.

12. Brooks CM and Koizumi K: Origin of the dorsal root reflex. J Neurophysiol 19: 60-74, 1956.

13. Evans RH and Long SK: Primary afferent depolarization in the rat spinal cord is mediated by pathways utilising NMDA and non-NMDA receptors. Neurosci Lett 100: 231-236, 1989.

14. Hackman JC and Davidoff RA: Dorsal root potentials in the isolated frog spinal cord: Amino acid neurotransmitters and magnesium ions. Neuroscience 41: 61-69, 1991

15. Bruera E: Mechanism of action of nonsteroidal anti-inflammatory drugs. Cancer Invest 16: 538-539, 1998.

16. Babot Z, Cristòfol R and Suñol C: Excitotoxic death induced by released glutamate in depolarized primary cultures of mouse cerebellar granule cells is dependent on GABAA receptors and niflumic acid-sensitive chloride channels. Eur J Neurosci 21: 103-112, 2005

17. Wallenstein MC: Attenuation of epileptogenesis by nonsteroidal anti-inflammatory drugs in the rat. Neuropharmacology 30 : 657-663, 1991

18. Bennett GJ and Xie YK: A peripheral mononeuropathy in rat that produces disorders of pain sensation like those seen in man. Pain 33: 87-107, 1988

19. Chen MG, Ma KT, Si JQ and Li L: Effects of niflumic acid on GABA-activated currents in isolated dorsal root ganglion neurons in rats with chronic constriction injury. J Shihezi Uniy (Natural Science) 32: 193-197, 2014 (In Chinese).

20. Zhu H, Ma KT, Li L, Zhang ZS, Li J and Si JQ: Changes of GABA-activated currents in isolated dorsal root ganglion neurons in rats with neuropathic pain. Zhongguo Ying Yong Sheng Li Xue Za Zhi 27: 376-379, 2011 (In Chinese).

21. Cheng HJ, Ma KT, Li L, Zhao L, Wang Y and Si JQ: Differential expression of alpha-adrenoceptor subtypes in rat dorsal root ganglion after chronic constriction injury. J Huazhong Univ Sci Technolog Med Sci 34: 322-329, 2014

22. Wang Y, Ma K, Li LI, Liu Y, Si J and Wan YU: Effect of non-genomic actions of thyroid hormones on the anaesthetic effect of propofol. Exp Ther Med 10: 959-965, 2015.
23. Li L, Zhao L, Wang Y, Ma KT, Shi WY, Wang YZ and Si JQ: PKCE mediates substance $P$ inhibition of GABAA receptors-mediated current in rat dorsal root ganglion. J Huazhong Univ Sci Technolog Med Sci 35: 1-9, 2015.

24. Li L, Wang Y, Ma KT, Cheng HJ, Zhao L and Si JQ: The effect of niflumic acid and blocker of calcium channel on the desensitization of gamma aminobutyric acid-activated current. Zhongguo Ying Yong Sheng Li Xue Za Zhi 29: 128-132, 2013 (In Chinese).

25. Li L, Li J, Ma KT, Cheng HJ, Zhao L, Wang Y and Si JQ: The effect of niflumic acid on gamma aminobutyric acid activated current in DRG neurons. Zhongguo Ying Yong Sheng Li Xue Za Zhi 29: 68-71, 2013 (In Chinese)

26. Si JQ, Zhang ZQ, Li CX, Wang LF, Yang YL and Li ZW: Modulatory effect of substance P on GABA-activated currents from rat dorsal root ganglion. Acta Pharmacol Sin 25: 623-629, 2004.

27. Bridges D, Thompson SW and Rice AS: Mechanisms of neuropathic pain. Br J Anaesth 87: 12-26, 2001.

28. Lian Y, Wang Y, Ma K, Zhao L, Zhang Z, Shang Y, Si J and Li L: Expression of gamma-aminobutyric acid type A receptor $\alpha 2$ subunit in the dorsal root ganglion of rats with sciatic nerve injury. Neural Regen Res 7: 2492-2499, 2012.

29. Wang Y, Li SY, Ma KT, Si JQ, Zhao L, Zhang ZS, Zhu H and $\mathrm{Li}$ L: Changes in presynaptic inhibition and the second message system of neuropathic pain model in rats. Chin J Mod Med 22: 9-14, 2012(In Chinese).

30. Gaunitz C, Schüttler A, Gillen Cand AllgaierC: Formalin-induced changes of NMDA receptor subunit expression in the spinal cord of the rat. Amino Acids 23: 177-182, 2002.

31. Carlton SM, Hargett GL and Coggeshall RE: Localization and activation of glutamate receptors in unmyelinated axons of rat glabrous skin. Neurosci Lett 197: 25-28, 1995.

32. Collin T, Chat M, Lucas MG, Moreno H, Racay P, Schwaller B, Marty A and Llano I: Developmental changes in parvalbumin regulate presynaptic Ca2+ signaling. J Neurosci 25: 96-107, 2005.

33. Caputo A, Caci E, Ferrera L, Pedemonte N, Barsanti C, Sondo E, Pfeffer U, Ravazzolo R, Zegarra-Moran O and Galietta LJ: TMEM16A, a membrane protein associated with calcium-dependent chloride channel activity. Science 322: 590-594, 2008.

34. Schroeder BC, Cheng T, Jan YN and Jan LY: Expression cloning of TMEM16A as a calcium-activated chloride channel subunit. Cell 134: 1019-1029, 2008.

35. Yang YD, Cho H, Koo JY, Tak MH, Cho Y, Shim WS, Park SP, Lee J, Lee B, Kim BM, et al: TMEM16A confers receptor-activated calcium-dependent chloride conductance. Nature 455: 1210-1215, 2008.

36. Cervero F and Laird JM: Mechanisms of touch-evoked pain (allodynia): A new model. Pain 68: 13-23, 1996. 